\title{
Pengaruh Kepemimpinan Transformasional dan Manajemen Pengetahuan terhadap Kinerja Organisasi: Organisasi Pembelajaran sebagai Mediator
}

\author{
Indra Muis1*, Puji Isyanto2 \\ Universitas Bina Insani, Universitas Buana Perjuangan Karawang \\ indramuis@ binainsani.ac.id, puji.isyanto@ubpkarawang.ac.id
}

*Penulis Korespondensi

$\begin{array}{ll}\text { Diajukan } & : 15 / 10 / 2021 \\ \text { Disetujui } & : 06 / 12 / 2021 \\ \text { Dipublikasi } & : 01 / 01 / 2022\end{array}$

\begin{abstract}
This study aims to explain the implementation of transformational leadership, knowledge management, learning organization, and organizational performance at private universities in West Java province and examine the effect of transformational leadership and knowledge management on organizational performance mediated by learning organization. The unit of analysis is the head of a private university campus in West Java Province, Indonesia. Respondents were 38 rectors and vice rectors from 59 private universities and the sampling technique is simple random sampling. Data are analyzed by using Partial Least Square (PLS) technique. The results show that all the measured independent variables and the mediator have very good values, but the dependent variable has good values and is still needed to be improved. In addition, transformational leadership and knowledge management have a significant and positive effect on learning organization. Learning organization also has a significant and positive effect on organizational performance. It can be concluded that all higher education leaders need to apply transformational leadership, knowledge management and learning organizations to improve their organizational performance. Leaders at the university level need to encourage all employees to develop learning strategies and provide learning opportunities for their employees. In addition, they also need to develop open discussion and communication between employees so that employees can share knowledge and skills to solve problems they face in doing their jobs.
\end{abstract}

Keywords: Transformational Leadership; Knowledge Management; Learning Organization; Organizational Performance; Private University

\section{PENDAHULUAN}

Jawa Barat merupakan salah satu dari 34 provinsi di Indonesia. Provinsi ini terletak di bagian barat Pulau Jawa. Pulau Jawa merupakan pulau terpadat di Indonesia dengan jumlah penduduk 48.270.000 jiwa pada tahun 2020 dengan luas wilayah 35.377,76 km2 (BPS, 2021). Terdapat 59 PTS di Provinsi Jawa Barat dengan 1.042 program studi dan 85.552 pendaftar baru setiap tahunnya. Jawa Barat merupakan provinsi dengan jumlah perguruan tinggi swasta terbanyak kedua di Indonesia. Jumlah PTS terbanyak pertama di Indonesia adalah Provinsi Jawa Timur. Ada 92 perguruan tinggi di Provinsi Jawa Timur. Pada tahun 2019 terdapat 3.129 perguruan tinggi dengan berbagai jenis di Indonesia (Ministry Research, 2019). Jenis-jenis perguruan tinggi adalah universitas, institut, sekolah tinggi, politeknik, akademi, dan community college. Ada 615 universitas di Indonesia. Perguruan Tinggi Negeri yang dimiliki dan dikelola oleh Pemerintah Indonesia berjumlah 63 dan Perguruan Tinggi Swasta yang dimiliki dan dikelola oleh masyarakat seluruhnya berjumlah 552 (Ministry Research, 2019). 
Salah satu permasalahan perguruan tinggi di Provinsi Jawa Barat adalah rendahnya Angka Partisipasi Kasar (APK). APK Provinsi Jawa Barat relatif rendah. Merupakan 19,93\% dari 35,69\% APK Nasional (Ministry Research, 2019). APK adalah rasio siswa sebenarnya yang mendaftar dengan populasi yang bisa mendaftar (dihitung untuk kelompok usia 19-23 tahun). APK menggambarkan kinerja perguruan tinggi. Perguruan Tinggi yang dikelola di bawah standar menghasilkan lulusan dengan keterampilan rendah. Lulusan dengan keterampilan rendah sulit untuk dipekerjakan karena persyaratan rekrutmen yang ketat. Hal itu berdampak pada meningkatnya angka pengangguran. Meningkatnya jumlah pengangguran lulusan membuat lulusan SMA kurang termotivasi untuk masuk perguruan tinggi. Akibatnya APK Provinsi Jawa Barat menjadi lebih rendah. Seperti terlihat pada Tabel 1 Provinsi Jawa Barat persentase bekerja sampai aktif secara ekonomi adalah 92,01\%. Lebih rendah dari provinsi lain di Pulau Jawa. Yang terendah adalah Provinsi Banten dengan persentase 91,89\%.

Tabel 1. Persentase Bekerja Aktif Secara Ekonomi di Provinsi-Provinsi di Pulau Jawa

\begin{tabular}{|c|c|c|}
\hline No & Provinsi & $\begin{array}{c}\text { Persentase Bekerja Aktif Secara } \\
\text { Ekonomi }\end{array}$ \\
\hline 1 & DKI Jakarta & $93.78 \%$ \\
\hline 2 & Jawa Barat & $92.01 \%$ \\
\hline 3 & Jawa Tengah & $95.51 \%$ \\
\hline 4 & DI Yogyakarta & $96.86 \%$ \\
\hline 5 & Jawa Timur & $96.08 \%$ \\
\hline 6 & Banten & $91.89 \%$ \\
\hline
\end{tabular}

Sumber tabel: Ministry Research (2019)

Tingginya angka pengangguran kemungkinan disebabkan oleh rendahnya kualitas lulusan perguruan tinggi. Ini adalah output dari rendahnya kualitas manajemen kampus. Mereka tidak direkrut karena tidak memenuhi kriteria rekrutmen perusahaan. Ini adalah masalah yang sangat penting untuk ditangani oleh universitas. Untuk mengatasi masalah ini, manajemen kampus perlu mencapai efisiensi dan efektivitas, membuat employee engagement program dan pelatihan karyawan, dan memastikan kepuasan kerja karyawan.

Telah ada beberapa penelitian sebelumnya mengenai pengaruh kepemimpinan transformasional dan manajemen pengetahuan terhadap kinerja organisasi. Kepemimpinan transformasional berpengaruh positif terhadap kinerja organisasi (Strukan, E. et al., 2017 Chen, J. X. et al., 2019; Naderi, A. et al., 2019; Arif, S. \& Akram, 2018) dan beberapa menjelaskan bahwa hubungan antara kepemimpinan transformasional dan kinerja organisasi dimediasi oleh sebuah variabel (Khan, H. U. R. et al., 2018; Manzoor, F. et al., 2019; Lin, H. C. et al., 2016; Obeidat, B. Y. \& Zyod, 2015). Manajemen pengetahuan berpengaruh positif terhadap kinerja organisasi (Abuaddous, H. Y. et al., 2018; Ha, S. T. et al., 2016;Iqbal, A. et al., 2019; Payal, R. et al., 2019 ). Beberapa menjelaskan bahwa manajemen pengetahuan dan hubungan kinerja organisasi dimediasi oleh variabel (Ngah, R. et al., 2016; Iqbal, A. et al., 2019; Obeso, M. et al., 2020; Alaarj, S. et al., 2016). Secara umum, penelitian-penelitian sebelumnya menggunakan kepemimpinan badan usaha yang berorientasi laba sebagai unit analisisnya. Dengan kata lain, masih jarang penelitian-penelitian sebelumnya yang menggunakan rektor perguruan tinggi swasta sebagai unit analisis penelitiannya selama ini. Akibatnya, pengaruh kepemimpinan transformasional dan manajemen pengetahuan sebagai variabel independen dan organisasi pembelajaran sebagai variabel mediasi terhadap kinerja organisasi universitas swasta sebagai variabel dependen dalam konteks universitas swasta nirlaba jarang dikupas dalam literatur. 
Penelitian ini bertujuan untuk menjelaskan implementasi kepemimpinan transformasional, manajemen pengetahuan, organisasi pembelajaran dan kinerja organisasi universitas swasta di provinsi Jawa Barat dan menguji pengaruh kepemimpinan transformasional dan manajemen pengetahuan terhadap kinerja organisasi yang dimediasi oleh organisasi pembelajaran. Untuk mencapai tujuan tersebut, dilakukan beberapa langkah. Pertama, beberapa penelitian sebelumnya dipelajari dengan seksama. Kedua, masalah penelitian dirumuskan. Setelah itu, instrumen penelitian dirumuskan untuk mengumpulkan data. Selanjutnya data dianalisis dengan metode Partial Least Square (PLS) menggunakan program Smart PLS Versi 2. Akhirnya, hasil analisis ditafsirkan sebagai temuan. Diharapkan penelitian ini secara teoritis memberikan kontribusi dalam bidang manajemen strategis. Secara praktis, pimpinan universitas mampu menerapkan hasil penelitian untuk meningkatkan kualitas manajemen kampus.

Penelitian ini memberikan dua kontribusi untuk literatur. Pertama, penelitian ini menggambarkan implementasi kepemimpinan transformasional, manajemen pengetahuan, organisasi pembelajaran, dan kinerja organisasi. Kedua, penelitian ini menawarkan konfirmasi bahwa ada variabel intervening dalam hubungan antara variabel independen dan variabel dependen. Pada penelitian ini variabel organisasi pembelajaran mengintervensi hubungan kepemimpinan transformasi dan manajemen pengetahuan dengan kinerja organisasi

\section{Pengembangan Hipotesis}

\section{STUDI LITERATUR}

\section{Kepemimpinan Transformasional dan Organisasi Pembelajaran}

Kepemimpinan transformasional merupakan bentuk kepemimpinan yang dapat mendorong para pengikutnya ke tingkat kinerja yang lebih tinggi (Herminingsih, 2020). Ini adalah praktik mengidentifikasi motivasi, nilai, dan kebutuhan atasan dan bawahan dengan tujuan memuaskan seluruh kelompok (Wardani, N. K., \& Eliyana, 2020). Dan, itu berfokus pada pengembangan pengikut dan kebutuhan mereka (Top, C. et al., 2020), dengan cara meningkatkan keterlibatan, komitmen, dan kinerja karyawan (Torlak, N. G., \& Kuzey, 2019). Dengan kata lain, kepemimpinan transformasional adalah seni memotivasi bawahan untuk mencapai kinerja tertinggi dalam melakukan pekerjaan mereka dan berkontribusi pada keberhasilan organisasi mereka dengan mengembangkan kompetensi mereka dan memenuhi kebutuhan mereka. Beberapa peneliti telah membuktikan pengaruh kepemimpinan transformasional pada organisasi pembelajaran. Mereka adalah Rijal (2016), Imran, M. K. et al., (2016), Vashdi, D. R. et al., (2019), dan Khan, H. U. R. et al., (2018). Indikator untuk mengukur kepemimpinan transformasional dalam penelitian ini adalah kesepakatan pimpinan universitas menerapkan active listening dan menyiapkan anggaran operasional tahunan bersama unit-unit di universitas; kesepakatan yang dilakukan pimpinan universitas diskusi terbuka dengan level manajemen rendah, unit, dosen dan mahasiswa; kesepakatan bahwa pimpinan universitas selalu menggarisbawahi dan fokus pada visi bersama yang ingin dicapai; dan kesepakatan bahwa pimpinan universitas tidak pernah marah kepada karyawan di depan umum.

Organisasi pembelajaran adalah organisasi yang selalu memberikan kesempatan kepada anggotanya dan mau meningkatkan diri untuk mencapai keberhasilan individu yang membawa keberhasilan organisasi (Yuesti, A., \& Sumantra, 2017). Dibutuhkan orang-orang yang secara intelektual ingin tahu tentang pekerjaan mereka, yang secara aktif merefleksikan pengalaman mereka, yang mengembangkan teori perubahan berbasis pengalaman dan terus mengujinya dalam praktik dengan rekan kerja, dan yang menggunakan pemahaman dan inisiatif mereka untuk berkontribusi pada pengembangan 
pengetahuan (Serrat, 2017). Kompetensi pekerja dapat menentukan kemajuan organisasi yang pada gilirannya akan mencerminkan kompetensi organisasi (Yuesti, A., \& Sumantra, 2017). Organisasi pembelajaran adalah organisasi yang memfasilitasi orang-orangnya untuk unggul dalam penciptaan, akuisisi, transfer, dan eksploitasi pengetahuan (Laeeque, S. H. et al., 2017). Dengan kata lain, organisasi pembelajaran adalah organisasi yang memberikan kesempatan kepada anggotanya untuk memperoleh, mentransfer, dan menggunakan pengetahuan dalam operasi organisasi. Indikator untuk mengukur organisasi pembelajaran dalam penelitian ini adalah kesepakatan bahwa universitas memperkenalkan strategi pembelajaran yang efektif kepada mahasiswa dan anggota fakultas, kesepakatan bahwa universitas universitas menciptakan kesempatan belajar berkelanjutan bagi anggota fakultas, dan kesepakatan bahwa para pemimpin di semua unit mendukung pembelajaran individu, pembelajaran tim, dan pembelajaran di semua unit.

Dengan mempertimbangkan beberapa temuan penelitian sebelumnya dapat dibuat hipotesis sebagai berikut:

H1: Kepemimpinan transfomasional berpengaruh positif terhadap organisasi pembelajaran

\section{Manajemen Pengetahuan dan Organisasi Pembelajaran}

Manajemen pengetahuan didefinisikan sebagai proses dan aktivitas yang membantu organisasi menghasilkan, memperoleh, menemukan, dan mengatur pengetahuan dan penggunaan serta menyebarkannya di antara orang-orang yang bekerja, dan mentransfer informasi dan pengalaman yang dimiliki organisasi dan menerapkannya dalam aktivitas manajemennya, seperti pengambilan keputusan, prosedur kerja, dan perencanaan strategis (Hussinki, H. et al., 2017). Ini adalah kemampuan strategis perusahaan untuk memperoleh pengetahuan, mengelola, dan memanfaatkan pengetahuan tentang pasar (Falasca, M. et al., 2017). Manajemen pengetahuan adalah mentransfer informasi penting dan keahlian sebagai bagian dari memori organisasi dan sifatnya dalam organisasi secara tidak terstruktur ke dalam pengetahuan terstruktur dalam rangka mencapai tujuan organisasi (Widiastuti, 2016). Berdasarkan definisi di atas dapat disimpulkan bahwa manajemen pengetahuan adalah proses memperoleh dan menyebarkan pengetahuan kepada karyawan dalam suatu organisasi dalam upaya untuk memanfaatkannya untuk menemukan solusi dari masalah yang dihadapi organisasi. Beberapa peneliti telah membuktikan efek dari manajemen pengetahuan pada organisasi pembelajaran. Mereka adalah Obeso, M. et al., (2020), Ngah, R. et al., (2016), dan Ishak, R., \& Mansor (2020). Indikator untuk mengukur manajemen pengetahuan dalam penelitian ini adalah kesepakatan bahwa universitas menggunakan penyimpanan seperti repositori online untuk menyimpan tulisan ilmiah dari dosen dan mahasiswa, kesepakatan bahwa universitas menggunakan berbagai sumber untuk memperoleh pengetahuan, dan kesepakatan bahwa universitas memfasilitasi media tacit knowledge dosen menjadi tulisan yang terdokumentasi dengan baik untuk mendukung implementasi manajemen pengetahuan.

Sebagaimana yang telah dijelaskan sebelumnya bahwa organisasi pembelajaran merupakan organisasi yang memberikan kesempatan kepada anggotanya untuk memperoleh, mentransfer, dan menggunakan pengetahuan dalam operasional organisasi dan didukung oleh beberapa hasil temuan yang mendukung maka dapat dibuat hipotesis sebagai berikut: 
Owner: Riset \& Jurnal Akuntansi

e-ISSN : 2548-9224 |p-ISSN : 2548-7507

Volume 6 Nomor 1, Januari 2022

DOI : https://doi.org/10.33395/owner.v6i1.543

$\mathrm{H} 2$ : Manajemen pengetahuan berpengaruh positif terhadap organisasi pembelajaran

\section{Organisasi Pembelajaran dan Kinerja Organisasi}

Sebagaimana yang telah dijelaskan sebelum bahwa organisasi pembelajaran merupakan organisasi yang memberikan kesempatan yang seluas-luasnya untuk mengembangkan potensi diri melalui belajar dan berbagi ilmu bersama. Beberapa peneliti telah membuktikan pengaruh organisasi pembelajaran terhadap kinerja organisasi. Mereka adalah Obeso, M. et al., (2020), Gomes, G., \& Wojahn (2017), Rehman, S. U. et al., (2019) dan Vasconcelos, V. N. D. S. A. et al., (2016).

Kinerja organisasi merupakan fenomena yang kompleks dan multidimensi dalam literatur bisnis (Al Khajeh, 2018). Itu bisa paling sederhana didefinisikan sebagai kinerja perusahaan dibandingkan dengan tujuan dan sasaran (Novak, 2017). Ini terdiri dari hasil organisasi atau keluaran aktual dari suatu organisasi, yang dapat diukur terhadap output, sasaran, dan sasaran yang diinginkan (Al Khajeh, 2018). Ada dua kategori kinerja organisasi: (a) kinerja organisasi subjektif seperti budaya, penerimaan sosial, dan tanggung jawab sosial perusahaan; tujuan pencapaian karyawan dan hasil kognitif; komitmen karyawan; keterlibatan karyawan; dan kepuasan kerja, dan (b) kinerja organisasi yang objektif seperti pangsa pasar, kinerja pasar keuangan, dan lain-lain (Jangsiriwattana, 2019). Mengacu pada postulat di atas, kinerja organisasi dapat didefinisikan sebagai output organisasi yang terukur, dibandingkan dengan tujuan dan sasaran organisasi. Indikator untuk mengukur kinerja organisasi adalah kesepakatan bahwa semua pegawai puas bekerja di universitas; dan kesepakatan bahwa semua karyawan menggunakan sumber daya secara efisien dalam melakukan pekerjaan mereka.

Dari beberapa hasil pemikiran tersebut dan didukung pula dengan hasil temuan penelitian terdahulu dapat dibuat hipotesis sebagai berikut:

H3: Organisasi pembelajaran berpengaruh positif terhadap kinerja organisasi

Selanjutnya dapat dirumuskan pula model konseptual penelitian sebagai berikut:

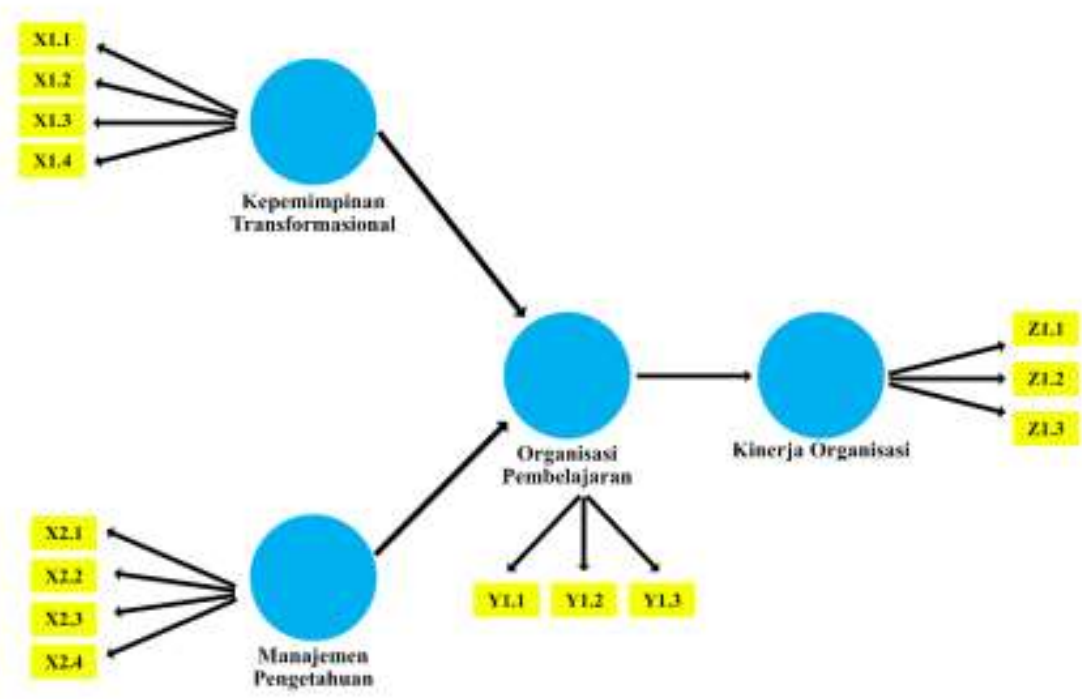

Gambar 1. Model Penelitian Struktural

Sumber tabel: Data Peneliti 


\section{METODE}

Penelitian ini merupakan sebuah penelitian yang mengunakan metode kuantitatif. Data dianalisis dengan mengunakan metode Partial Least Square (PLS) dengan program Smart PLS Versi 2. Penelitian ini menjelaskan variabel-variabel yang diukur dan menguji hubungan antar variabel seperti hubungan antara kepemimpinan transformasional dan manajemen pengetahuan terhadap kinerja organisasi perguruan tinggi swasta Jawa Barat yang dimediasi oleh organisasi pembelajaran. Variabel bebas penelitian ini adalah kepemimpinan transformasional dan manajemen pengetahuan. Variabel terikatnya adalah kinerja organisasi sedangkan variabel interveningnya adalah organisasi pembelajaran.

Responden merupakan para rektor atau wakil rektor yang mewakili universitas swasta di Provinsi Jawa Barat. Alasan menjadikan para rektor atau wakil rektor menjadi responden adalah karena mereka yang mengalami dan mengimplementasikan semua variabel yang diukur. Responden berjumlah 38 responden dari total populasi 59 universitas swasta. Teknik sampling yang digunakan adalah simple random sampling. Alasan pengunaan simple random sampling adalah agar setiap anggota populasi memiliki kesempatan untuk terpilih menjadi responden secara adil.

Populasi dalam penelitian ini adalah 59 universitas swasta di Provinsi Jawa Barat. Kebutuhan sampel setelah dihitung dengan mengunakan sample size calculator dengan margin of error 5\% dan confidence level $90 \%$ adalah 49 responden. Kuesioner dikirim secara online ke 49 rektor secara acak. Sebanyak 38 rektor bersedia ambil bagian dan berperan sebagai responden. Yang lain enggan untuk ambil bagian. Beberapa dari mereka menyampaikan mengapa mereka enggan untuk mengambil bagian. Mereka mengakui bahwa isi kuesioner sangat pribadi dan harus dirahasiakan.

Penelitian ini menggunakan dua jenis data yaitu data primer dan data sekunder. Data sekunder digunakan untuk mendukung data primer yang terdiri dari studi literatur, jurnal dan informasi lainnya. Sedangkan data primer diperoleh dari hasil kuisioner oleh responden. Seluruh variabel independen, intervening dan dependen dalam penelitian ini diukur dengan indikator yang digunakan oleh Yamin (2020).

Tabel 2. Indikator untuk Mengukur Kepemimpinan Transformasional

\begin{tabular}{|c|l|}
\hline NO & \multicolumn{1}{|c|}{ INDIKATOR } \\
\hline 1 & $\begin{array}{l}\text { Para pemimpin di tingkat Rektorat dan Dekanat selalu menerapkan Active } \\
\text { listening dan menyusun Rencana Kegiatan dan Anggaran Tahunan bersama- } \\
\text { sama dengan unit kerja yang ada di lingkungan universitas }\end{array}$ \\
\hline 2 & $\begin{array}{l}\text { Para pemimpin di tingkat Rektorat dan Dekanat selalu melakukan diskusi } \\
\text { terbuka dengan para ka. Prodi, kepala lembaga, kepala biro, kepala bagian, } \\
\text { tenaga kependidikan dan civitas akademika }\end{array}$ \\
\hline 3 & $\begin{array}{l}\text { Para pemimpin di tingkat Rektorat dan Dekanat selalu menitik beratkan pada } \\
\text { pencapaian visi bersama }\end{array}$ \\
\hline 4 & $\begin{array}{l}\text { Para pemimpin di tingkat Rektorat dan Dekanat tidak pernah memarahi } \\
\text { pegawai universitas di depan umum }\end{array}$ \\
\hline
\end{tabular}

Sumber tabel: Data Peneliti

Tabel 3. Indikator untuk Mengukur Manajemen Pengetahuan

\begin{tabular}{|c|l|}
\hline NO & \multicolumn{1}{|c|}{ INDIKATORS } \\
\hline $\mathbf{1}$ & $\begin{array}{l}\text { Universitas kami mengunakan fasilitas penyimpanan seperti repository online } \\
\text { untuk menyimpan karya-karya ilmiah civitas akademika }\end{array}$ \\
\hline $\mathbf{2}$ & $\begin{array}{l}\text { Universitas kami mengunakan beragam sumber untuk memperoleh ilmu } \\
\text { pengetahuan }\end{array}$ \\
\hline
\end{tabular}


Owner: Riset \& Jurnal Akuntansi

e-ISSN : 2548-9224 |p-ISSN : 2548-7507

Volume 6 Nomor 1, Januari 2022

DOI : https://doi.org/10.33395/owner.v6i1.543

\begin{tabular}{|c|l|}
\hline 3 & $\begin{array}{l}\text { Universitas kami mengunakan sistem dan struktur untuk klasifikasi ilmu } \\
\text { pengetahuan sehingga mudah bagi sivitas akademika dan tenaga kependidikan } \\
\text { untuk mengaksesnya. }\end{array}$ \\
\hline 4 & $\begin{array}{l}\text { Universitas kami memfasilitasi civitas akademika dan tenaga kependidikan } \\
\text { media yang menampung tacit knowledge menjadi tulisan-tulisan yang } \\
\text { terdokumentasi dengan baik untuk mendukung implementasi Knowledge } \\
\text { Management. }\end{array}$ \\
\hline
\end{tabular}

Sumber tabel: Data Peneliti

Tabel 4. Indikator untuk Mengukur Pembelajaran Organisasi

\begin{tabular}{|c|l|}
\hline NO & \multicolumn{1}{|c|}{ INDIKATOR } \\
\hline 1 & $\begin{array}{l}\text { Universitas kami mengenalkan strategi-strategi pembelajaran yang efektif } \\
\text { kepada civitas akademika }\end{array}$ \\
\hline 2 & $\begin{array}{l}\text { Universitas kami menciptakan peluang pembelajaran yang kekesinambungan } \\
\text { bagi sivitas akademikan dan tenaga kependidikan }\end{array}$ \\
\hline 3 & $\begin{array}{l}\text { Para pemimpin di tingkat rektorat dan dekanat pada Universitas kami sangat } \\
\text { mendukung pembelajaran pada tingkat individu, tim dan unit kerja }\end{array}$ \\
\hline
\end{tabular}

Sumber tabel: Data Peneliti

Tabel 5. Indikator untuk Mengukur Kinerja Organisasi

\begin{tabular}{|c|l|}
\hline NO & \multicolumn{1}{|c|}{ INDIKATOR } \\
\hline 1 & Seluruh karyawan kami puas bekerja di universitas kami \\
\hline 2 & Seluruh lulusan kami memiliki kualitas kerja yang tinggi \\
\hline 3 & $\begin{array}{l}\text { Seluruh karyawan Kami mengunakan sumberdaya secara efisien dalam } \\
\text { melakukan pekerjaan. }\end{array}$ \\
\hline
\end{tabular}

Sumber tabel: Data Peneliti

\section{HASIL}

Persepsi responden mengenai setiap dimensi pada setiap variabel dinilai dalam 5 (lima) kategori yaitu: Sangat Baik $(4,21-5,00)$, Baik $(3,41-4,20)$, Cukup Baik $(2,61-$ $3,40)$, Tidak Baik $(1,81-2,60)$, dan very poor $(<1,81)$.(Sugiyono, 2018)

Tabel 6. Skor Semua Variabel

\begin{tabular}{|c|l|c|c|}
\hline NO & \multicolumn{1}{|c|}{ VARIABEL } & SKOR & KETERANGAN \\
\hline 1 & Kepemimpinan Transformasional & 4.44 & Sangat Baik \\
\hline 2 & Manajemen Pengetahuan & 4.45 & Sangat Baik \\
\hline 3 & Organisasi Pembelajaran & 4.67 & Sangat Baik \\
\hline 4 & Kinerja Organisasi & 4.16 & Baik \\
\hline
\end{tabular}

Sumber tabel: Data Peneliti

Tabel 7. Skor Kepemimpinan Transformational

\begin{tabular}{|c|l|c|c|}
\hline NO & \multicolumn{1}{|c|}{ INDIKATOR } & SKOR & KETERANGAN \\
\hline 1 & $\begin{array}{l}\text { Para pemimpin di tingkat Rektorat dan } \\
\text { Dekanat selalu menerapkan Active listening } \\
\text { dan menyusun Rencana Kegiatan dan }\end{array}$ & 4.71 & Sangat Baik \\
& $\begin{array}{l}\text { Anggaran Tahunan bersama-sama dengan } \\
\text { unit kerja yang ada di lingkungan } \\
\text { universitas }\end{array}$ & & \\
\hline 2 & $\begin{array}{l}\text { Para pemimpin di tingkat Rektorat dan } \\
\text { Dekanat selalu melakukan diskusi terbuka } \\
\text { dengan para ka. Prodi, kepala lembaga, } \\
\text { kepala biro, kepala bagian, tenaga }\end{array}$ & & Sangat Baik \\
\hline
\end{tabular}


Owner: Riset \& Jurnal Akuntansi

e-ISSN : 2548-9224 |p-ISSN : 2548-7507

Volume 6 Nomor 1, Januari 2022

DOI : https://doi.org/10.33395/owner.v6i1.543

\begin{tabular}{|c|l|c|c|}
\hline & kependidikan dan civitas akademika & & \\
\hline 3 & $\begin{array}{l}\text { Para pemimpin di tingkat Rektorat dan } \\
\text { Dekanat selalu menitik beratkan pada } \\
\text { pencapaian visi bersama }\end{array}$ & 4.63 & Baik \\
\hline 4 & $\begin{array}{l}\text { Para pemimpin di tingkat Rektorat dan } \\
\text { Dekanat tidak pernah memarahi pegawai } \\
\text { universitas di depan umum }\end{array}$ & 4.16 & \\
\hline
\end{tabular}

Sumber tabel: Data Peneliti

Tabel 8. Skor Manajemen Pengetahuan

\begin{tabular}{|c|l|c|c|}
\hline NO & \multicolumn{1}{|c|}{ INDIKATORS } & SKOR & KETERANGAN \\
\hline 1 & $\begin{array}{l}\text { Universitas kami mengunakan fasilitas } \\
\text { penyimpanan seperti repository online untuk } \\
\text { menyimpan karya-karya ilmiah civitas } \\
\text { akademika }\end{array}$ & Sangat Baik \\
\hline 2 & $\begin{array}{l}\text { Universitas kami mengunakan beragam } \\
\text { sumber untuk memperoleh ilmu } \\
\text { pengetahuan }\end{array}$ & 4,79 & Sangat Baik \\
\hline 3 & $\begin{array}{l}\text { Universitas kami mengunakan sistem dan } \\
\text { struktur untuk klasifikasi ilmu pengetahuan } \\
\text { sehingga mudah bagi sivitas akademika dan } \\
\text { tenaga kependidikan untuk mengaksesnya. }\end{array}$ & 4,37 & Sangat Baik \\
\hline 4 & $\begin{array}{l}\text { Universitas kami memfasilitasi civitas } \\
\text { akademika dan tenaga kependidikan media } \\
\text { yang menampung tacit knowledge menjadi } \\
\text { tulisan-tulisan yang terdokumentasi dengan } \\
\text { baik untuk mendukung implementasi } \\
\text { Knowledge Management. }\end{array}$ & & \\
\hline
\end{tabular}

Sumber tabel: Data Peneliti

Tabel 9. Skor Kinerja Organisasi Pembelajaran

\begin{tabular}{|c|l|c|c|}
\hline NO & \multicolumn{1}{|c|}{ INDIKATOR } & SKOR & KETERANGAN \\
\hline 1 & $\begin{array}{l}\text { Universitas kami mengenalkan strategi- } \\
\text { strategi pembelajaran yang efektif kepada } \\
\text { civitas akademika }\end{array}$ & 4,55 & Sangat Baik \\
\hline 2 & $\begin{array}{l}\text { Universitas kami menciptakan peluang } \\
\text { pembelajaran yang kekesinambungan bagi } \\
\text { sivitas akademikan dan tenaga } \\
\text { kependidikan }\end{array}$ & 4,53 & Sangat Baik \\
\hline 3 & $\begin{array}{l}\text { Para pemimpin di tingkat rektorat dan } \\
\text { dekanat pada Universitas kami sangat } \\
\text { mendukung pembelajaran pada tingkat } \\
\text { individu, tim dan unit kerja }\end{array}$ & 4,61 & \\
\hline
\end{tabular}

Sumber tabel: Data Peneliti

Tabel 10. Skor Kinerja Organisasi

\begin{tabular}{|c|l|c|c|}
\hline NO & \multicolumn{1}{|c|}{ INDIKATOR } & SKOR & KETERANGAN \\
\hline 1 & $\begin{array}{l}\text { Seluruh karyawan kami puas bekerja di } \\
\text { universitas kami }\end{array}$ & 4.18 & Baik \\
\hline 2 & Seluruh lulusan kami memiliki kualitas & 4.16 & Baik \\
\hline
\end{tabular}


Owner: Riset \& Jurnal Akuntansi

e-ISSN : 2548-9224 |p-ISSN : 2548-7507

Volume 6 Nomor 1, Januari 2022

DOI : https://doi.org/10.33395/owner.v6i1.543

\begin{tabular}{|c|l|c|c|}
\hline 3 & kerja yang tinggi & & Baik \\
\hline $\begin{array}{l}\text { Seluruh karyawan Kami mengunakan } \\
\text { melakukan pekerjaan. }\end{array}$ & 4.16 & \\
\hline
\end{tabular}

\section{Sumber tabel: Data Peneliti}

Selanjutnya dijelaskan hasil pengukuran Outer Model dan pengujian inner model struktural. Pada pengukuran outer model terdapat uji validitas yang dapat dilihat dari hasil untuk outer loadings, hasil dari cross loadings, dan Average Variance Extracted (AVE). Pada pengukuran outer model juga dilakukan uji reliabilitas yang dapat dilihat dari nilai composite reliability, Cronbach' Alpha dan communality. Sedangkan, hasil pengujian inner model dapat dilihat dari $R$ Square dan $R$ Square Adjusted.

Pada uji validitas, suatu indikator dianggap valid jika faktor pemuatannya di atas 0,5. (Sugiyono, 2018). Output SmartPLS untuk loading factor yang dihitung melalui Algoritma PLS menyajikan hasil sebagai berikut:

Tabel 11. Hasil untuk Outer Loadings

\begin{tabular}{|c|c|c|c|c|}
\hline Indikator & $\begin{array}{c}\text { Manajemen } \\
\text { Pengetahuan }\end{array}$ & $\begin{array}{c}\text { Organisasi } \\
\text { Pembelajaran }\end{array}$ & $\begin{array}{c}\text { Kinerja } \\
\text { Organisasi }\end{array}$ & $\begin{array}{c}\text { Kepemimpinan } \\
\text { Transformasi }\end{array}$ \\
\hline $\mathrm{X} 1.3$ & & & & 1,000 \\
\hline $\mathrm{X} 2.1$ & 0,848 & & & \\
\hline $\mathrm{X} 2.3$ & 0,870 & & & \\
\hline $\mathrm{X} 2.4$ & 0,879 & & & \\
\hline $\mathrm{Y} 1.1$ & & 0,913 & & \\
\hline $\mathrm{Y} 1.2$ & & 0,914 & & \\
\hline $\mathrm{Z} 1.1$ & & & 0,944 & \\
\hline $\mathrm{Z} 1.2$ & & & 0,936 & \\
\hline
\end{tabular}

Sumber tabel: Data primer yang diolah

Nilai loading factor dianggap valid atau memenuhi validitas konvergen jika melebihi 0,5 (Sugiyono, 2018). Loading factor terendah adalah 0,848 seperti terlihat pada Tabel 11 sehingga indikator tersebut valid. Loading factor masing-masing indikator dapat dilihat dalam model penelitian struktural pada Gambar 2 berikut ini.

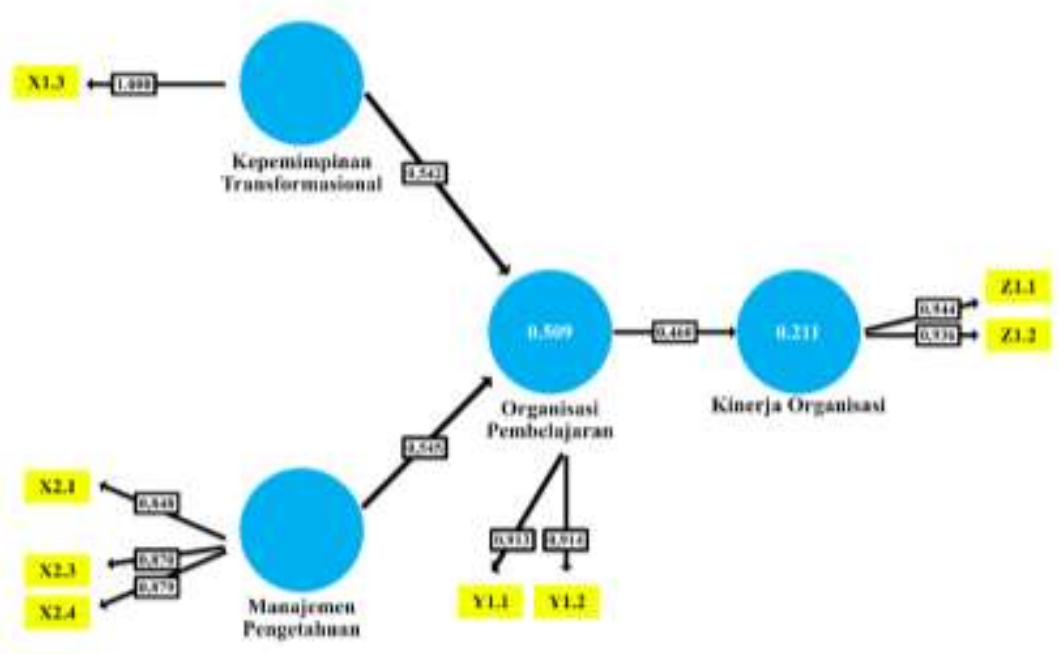

Gambar 2.Loading Factor Value

Sumber gambar: Data primer yang diolah 
di SmartPLS, indikator penelitian diuji validitas diskriminan dengan cross loading seperti yang ditunjukkan pada Tabel 12.

Tabel 12. Hasil untuk Cross Loadings

\begin{tabular}{|c|c|c|c|c|}
\hline Indikator & $\begin{array}{c}\text { Manajemen } \\
\text { Pengetahuan }\end{array}$ & $\begin{array}{c}\text { Organisasi } \\
\text { Pembelajaran }\end{array}$ & $\begin{array}{c}\text { Kinerja } \\
\text { Organisasi }\end{array}$ & $\begin{array}{c}\text { Kepemimpinan } \\
\text { Transformasional }\end{array}$ \\
\hline $\mathrm{X} 1.3$ & $-0,139$ & 0,466 & $-0,063$ & 1,000 \\
\hline $\mathrm{X} 2.1$ & 0,848 & 0,400 & 0,655 & $-0,081$ \\
\hline $\mathrm{X} 2.3$ & 0,870 & 0,438 & 0,593 & $-0,145$ \\
\hline $\mathrm{X} 2.4$ & 0,879 & 0,378 & 0,484 & $-0,132$ \\
\hline $\mathrm{Y} 1.1$ & 0,503 & 0,913 & 0,397 & 0,370 \\
\hline $\mathrm{Y} 1.2$ & 0,356 & 0,914 & 0,443 & 0,481 \\
\hline $\mathrm{Z} 1.1$ & 0,746 & 0,446 & 0,944 & $-0,087$ \\
\hline Z1.2 & 0,505 & 0,418 & 0,936 & $-0,030$ \\
\hline
\end{tabular}

Sumber tabel: Data primer yang diolah

Suatu indikator dikatakan valid jika loading factor lebih tinggi dari loading factor konstruk lainnya. Beberapa indikator dalam variabel yang diukur telah dihilangkan dalam proses pengujian. Penghapusan tersebut merupakan upaya untuk mendapatkan koefisien korelasi yang cukup. Seperti yang ditunjukkan pada Tabel 12 faktor pemuatan untuk kepemimpinan transformasional (X.1.3) memiliki faktor pemuatan yang lebih tinggi untuk konstruk kepemimpinan transformasional daripada konstruk lainnya. Sebagai gambaran, loading factor X.1.3 untuk kepemimpinan transformasional adalah 1.000 yang lebih tinggi dari loading factor untuk manajemen pengetahuan $(-0,139)$, organisasi pembelajaran $(0,466)$, dan kinerja organisasi $(-0,063)$.

Cara lain untuk mengetahui validitas diskriminan adalah dengan melihat akar kuadrat dari nilai Average Variance Extracted (AVE). Nilainya disarankan di atas 0,5 (Sugiyono, 2018). Seperti terlihat pada Tabel 13 nilai AVE diatas 0,5 untuk semua konstruk yang terdapat dalam model penelitian. Nilai AVE terendah adalah 0,750 pada konstruk manajemen pengetahuan.

Tabel 13. Average Variance Extracted (AVE)

\begin{tabular}{|l|c|}
\hline \multicolumn{1}{|c|}{ Variabel } & $\begin{array}{c}\text { Average Variance } \\
\text { Extracted }(\text { AVE) }\end{array}$ \\
\hline Manajemen Pengetahuan & 0,750 \\
\hline Organisasi Pembelajaran & 0,835 \\
\hline Kinerja Organisasi & 0,884 \\
\hline Kepemimpinan Transformasional & 1,000 \\
\hline
\end{tabular}

Sumber tabel: Data primer yang diolah

B. Uji Reliabilitas

Uji reliabilitas dilakukan dengan cara mempertimbangkan nilai komposit reliabilitas indikator pengukur konstruk. Hasil reliabilitas komposit akan dianggap sebagai nilai yang memuaskan bila di atas 0,7 (Sugiyono, 2018). 
Owner: Riset \& Jurnal Akuntansi

e-ISSN : 2548-9224 |p-ISSN : 2548-7507

Volume 6 Nomor 1, Januari 2022

DOI : https://doi.org/10.33395/owner.v6i1.543

Table 14. Composite Reliability

\begin{tabular}{|l|r|}
\hline \multicolumn{1}{|c|}{ Variabel } & Composite Reliability \\
\hline Manajemen Pengetahuan & 0,900 \\
\hline Organisasi Pembelajaran & 0,910 \\
\hline Kinerja Organisasi & 0,939 \\
\hline Kepemimpinan Transformasional & 1,000 \\
\hline
\end{tabular}

Sumber tabel: Data primer yang diolah

Seperti yang ditunjukkan pada Tabel 14 nilai reliabilitas komposit di atas 0,7 untuk semua konstruk. Hal ini menunjukkan bahwa semua konstruk dalam model yang diestimasi telah memenuhi kriteria validitas diskriminan. Dalam penelitian ini nilai composite reliability terendah adalah 0,900 pada konstruk manajemen pengetahuan. Uji reliabilitas diperkuat dengan Cronbach's alpha sebagai berikut:

Table 15. Cronbach's Alpha

\begin{tabular}{|l|r|}
\hline \multicolumn{1}{|c|}{ Variabel } & Cronbach' s Alpha \\
\hline Manajemen Pengetahuan & 0,833 \\
\hline Organisasi Pembelajaran & 0,802 \\
\hline Kinerja Organisasi & 0,869 \\
\hline Kepemimpinan Transformasional & 1,000 \\
\hline
\end{tabular}

Sumber tabel: Data primer yang diolah

Tabel 15 menunjukkan nilai Cronbach's alpha untuk semua konstruksi di atas 0,6. (Sugiyono, 2018). Nilai terendah adalah 0, 802 dalam konstruk organisasi pembelajaran karena nilai yang direkomendasikan di atas 0,6. Selanjutnya tabel 6 menunjukkan Communality dengan program SmartPLS Versi 2 sebagai berikut:

Tabel 16. Communality

\begin{tabular}{|l|r|}
\hline \multicolumn{1}{|c|}{ Variabel } & Communality \\
\hline Manajemen Pengetahuan & 0,750 \\
\hline Organisasi Pembelajaran & 0,835 \\
\hline Kinerja Organisasi & 0,884 \\
\hline Kepemimpinan Transformasional & 1,000 \\
\hline
\end{tabular}

Sumber tabel: Data primer yang diolah

Tabel 16 menunjukkan bahwa nilai komunalitas pada semua konstruk di atas 0,5, memperkuat hasil pengujian dengan composite reliability dan Cronbach's alpha.

Setelah model yang diestimasi memenuhi kriteria outer model, selanjutnya dilakukan pengujian model struktural. Tabel berikut menunjukkan nilai R-Square dalam konstruk.

Tabel 17. R Square dan $R$ Square Adjusted

\begin{tabular}{|l|r|r|}
\hline \multicolumn{1}{|c|}{ Variabel } & R Square & \multicolumn{1}{c|}{$\boldsymbol{R}$ Square Adjusted } \\
\hline Organisasi Pembelajaran & 0,509 & 0,481 \\
\hline Kinerja Organisasi & 0,211 & 0,189 \\
\hline
\end{tabular}

Sumber tabel: Data primer yang diolah

Tabel 17 menunjukkan bahwa organisasi pembelajaran mampu menjelaskan variabel kinerja organisasi. 
Owner: Riset \& Jurnal Akuntansi

e-ISSN : 2548-9224 |p-ISSN : 2548-7507

Volume 6 Nomor 1, Januari 2022

DOI : $\underline{\text { https://doi.org/10.33395/owner.v6i1.543 }}$

Tabel 18. Pengujian Hipotesis

\begin{tabular}{|c|l|l|l|l|l|}
\hline \multicolumn{6}{|c|}{ Original Sample (O) Sample Mean (M) Standard Deviation (STDEV) T Statistics } \\
\hline Hipotesis & \multicolumn{1}{|c|}{$\boldsymbol{O}$} & $\boldsymbol{M}$ & \multicolumn{1}{|c|}{ STDEV } & O/STDEV & P Values \\
\hline MP -> OP & 0.545 & 0.558 & 0.094 & 5.790 & 0.000 \\
\hline OP -> KO & 0.460 & 0.474 & 0.113 & 4.086 & 0.000 \\
\hline KT -> OP & 0.542 & 0.522 & 0.131 & 4.142 & 0.000 \\
\hline
\end{tabular}

Sumber tabel: Data primer yang diolah

Seperti yang ditunjukkan pada tabel $18 \mathrm{t}$-statistik pada hubungan antara manajemen pengetahuan dan organisasi pembelajaran adalah sebesar 5,780 >t tabel $(1,66)$. Nilai estimasi sampel asli adalah 0,545, menunjukkan bahwa arah hubungan antara manajemen pengetahuan dan organisasi pembelajaran adalah positif. Dengan demikian, hipotesis H1 yang menyatakan bahwa manajemen pengetahuan berpengaruh positif terhadap organisasi pembelajaran diterima.

Tabel 18 juga menunjukkan bahwa t-statistik pada hubungan antara kepemimpinan transformasional dan organisasi pembelajaran adalah sebesar 4,142 > t tabel (1,66023). Nilai estimasi sampel asli adalah 0,542 menunjukkan bahwa arah hubungan antara kepemimpinan transformasional dan organisasi pembelajaran adalah positif. Dengan demikian, hipotesis $\mathrm{H} 2$ dalam penelitian ini yang menyatakan bahwa kepemimpinan transformasional berpengaruh positif terhadap organisasi pembelajaran juga diterima.

Tabel 18 menunjukkan bahwa t-statistik pada hubungan antara organisasi pembelajaran dan kinerja organisasi adalah sebesar 4,086 < t tabel $(1,66)$. Nilai estimasi sampel asli adalah 0,460 yang menunjukkan bahwa arah hubungan antara organisasi pembelajaran dan kinerja organisasi adalah positif. Dengan demikian, hipotesis H3 dalam penelitian ini yang menyatakan bahwa organisasi pembelajaran berpengaruh positif terhadap kinerja organisasi juga dapat diterima.

\section{PEMBAHASAN}

Secara keseluruhan, hasil penelitian menunjukkan bahwa kepemimpinan transformasional berpengaruh positif terhadap organisasi pembelajaran. Artinya, semua pimpinan di tingkat universitas wajib berkomunikasi dan berdiskusi secara terbuka. Diskusi terbuka di antara para pemimpin ini akan mendorong semua karyawan untuk berbagi pengetahuan dan keterampilan mereka dan membuat karyawan ingin mempelajari hal-hal baru yang berkaitan dengan pekerjaan dan karier mereka. Ini adalah momen yang baik bagi para pemimpin untuk mendorong bawahannya untuk belajar lebih banyak tentang strategi pembelajaran dan memfasilitasi bawahan dengan program pelatihan berkelanjutan. Temuan ini mengkonfirmasi penelitian sebelumnya yang dilakukan oleh Rijal (2016), Imran, M. K. et al., (2016), Vashdi, D. R. et al., (2019), Khan, H. U. R. et al., (2018).

Manajemen pengetahuan juga mempengaruhi organisasi pembelajaran. Ini menyiratkan bahwa pemimpin universitas menyediakan semua karyawan dengan repositori online untuk memungkinkan karyawan mengakses pengetahuan dalam e-book dan e-journal dan memperluas pengetahuan mereka. Selain itu, pimpinan juga menyediakan sistem dan struktur untuk mengklasifikasikan ilmu dan ilmu agar karyawan mudah dan cepat mempelajari dokumen. Para pemimpin juga mendorong semua karyawan untuk menulis tacit knowledge mereka untuk berbagi pengalaman dengan karyawan lain melalui dokumen tertulis yang mereka hasilkan dan arsipkan di repositori. Repositori, sistem dan struktur klasifikasi pengetahuan dan ilmu pengetahuan serta dokumentasi pengetahuan tacit akan memotivasi karyawan untuk memperkaya strategi pembelajaran mereka dan mengambil kesempatan untuk belajar. Penelitian ini mengkonfirmasi 
penelitian sebelumnya yang dilakukan oleh Obeso, M. et al., (2020), Ngah, R. et al., (2016), dan Ishak, R., \& Mansor (2020)

Karena organisasi pembelajaran juga mempengaruhi kinerja organisasi, dapat dijelaskan bahwa organisasi pembelajaran, yang disediakan oleh universitas untuk karyawannya dan strategi pembelajaran yang telah memperkaya diri karyawan, menghasilkan kepuasan kerja karyawan dan lulusan dengan keterampilan dan pengetahuan yang baik. Jadi, dalam hal hubungan organisasi pembelajaran, penelitian ini mendukung penelitian sebelumnya yang dilakukan oleh Obeso, M. et al (2020), Gomes, G., \& Wojahn (2017), Rehman, S. U. et al., (2019), Vasconcelos, V. N. D. S. A. et al., (2016).

Implikasi teoretis dari temuan penelitian adalah bahwa kepemimpinan transformational mempengaruhi organisasi pembelajaran secara signifikan dan positif dan bahwa hubungan kepemimpinan transformasional dengan kinerja organisasi dimediasi oleh organisasi pembelajaran. Manajemen pengetahuan juga mempengaruhi organisasi pembelajaran secara signifikan dan positif dan bahwa hubungan antara manajemen pengetahuan dan kinerja organisasi juga dimediasi oleh organisasi pembelajaran.

Untuk kontribusi praktis, penting untuk dicatat bahwa para pemimpin universitas menggarisbawahi dan memfokuskan atau memberikan perhatian besar untuk mencapai visi bersama dalam semangat kerja tim. Disarankan kepada pimpinan universitas untuk menyediakan repositori online untuk menyimpan tulisan-tulisan ilmiah dosen dan mahasiswa serta membuat sistem dan struktur untuk mengklasifikasikan dokumen-dokumen ilmiah agar dapat diakses oleh dosen dan mahasiswa. Selain itu pimpinan universitas perlu memfasilitasi media untuk tacit knowledge para dosen agar terdokumentasi dengan baik secara tertulis untuk mendukung implementasi manajemen pengetahuan. Pimpinan universitas juga perlu memperkenalkan kepada dosen dan mahasiswa strategi pembelajaran yang efektif dan menciptakan kesempatan belajar yang berkelanjutan bagi mereka untuk memperkuat kepuasan karyawan dan menciptakan lulusan berkualitas tinggi.

\section{KESIMPULAN}

Terdapat 2 (dua) temuan utama dalam penelitian ini. Temuan pertama adalah bahwa implementasi kepemimpinan transformasional, manajemen pengetahuan, dan organisasi pembelajaran telah dilakukan dengan sangat baik pada universitas swasta di Provinsi Jawa Barat. Para pimpinan universitas swasta di Provinsi Jawa Barat perlu mempertahankan prestasi tersebut. Implementasi kinerja organisasi perguruan tinggi swasta di Provinsi Jawa Barat dilaksanakan dengan baik dan masih sangat perlu ditingkatkan. Temuan kedua adalah bahwa terdapat pengaruh positif kepemimpinan transformasional dan manajemen pengetahuan terhadap organisasi pembelajaran. Ditemukan juga bahwa organisasi pembelajaran mempengaruhi kinerja organisasi dan memediasi hubungan antara kepemimpinan transformasional dan manajemen pengetahuan terhadap kinerja organisasi universitas swasta di Provinsi Jawa Barat. Dari hubungan antar variabel tersebut dapat dimaknai bahwa untuk meningkatkan kinerja organisasi, pimpinan universitas swasta perlu mendorong seluruh karyawan dan dosen untuk mengembangkan strategi pembelajaran dan memberikan kesempatan belajar bagi karyawannya. Selain itu, pimpinan universitas juga mengembangkan diskusi dan komunikasi terbuka di antara karyawan sehingga karyawan dapat berbagi pengetahuan dan keterampilan untuk memecahkan masalah yang mereka hadapi dalam melakukan pekerjaan mereka.

Penelitian ini memiliki beberapa keterbatasan. Pertama, jumlah responden di bawah jumlah ideal. Dari 49 responden yang ditargetkan hanya 38 responden yang bersedia untuk mengisi kuesioner. Kedua, responden hanyalah rektor dan wakil rektor. Ada baiknya respondennya merupakan pimpinan di tingkat fakultas dan program studi serta biro yang ada di universitas. Selanjutnya penelitian ini baru melihat hubungan variabel bebas dan variabel terikat yang dimediasi oleh mediator. Tentunya masih terbuka kemungkinan terdapat hubungan langsung antara varibel bebas dan variabel terikat. Lebih jauh lagi, terdapat variabel-variabel bebas lainnya yang memiliki kemungkinan untuk mempengaruhi kinerja organisasi. 
Berdasarkan kepada keterbatasan-keterbatasan tersebut, selanjutnya dapat dilakukan penelitian dengan variabel bebas lain yang berkemungkinan mempengaruhi kinerja organisasi seperti budaya organisasi, employee engagement, motivasi karyawan dan lain-lain untuk penelitian untuk masa yang akan datang dengan lingkup geografi yang lebih luas, dan responden yang lebuh beragam.

\section{UCAPAN TERIMA KASIH}

Riset ini merupakan riset bersama antara dosen Universitas Bina Insani dan Dosen Universitas Bauna Perjuangan Karawang sebagai bagian dari implementasi kesepakatan kerjasama. Ucapan terima kasih disampaikan kepada segenap pimpinan Universitas Bina Insani dan Universitas Buana Perjuangan Karawang atas semua dukungan baik moril maupun materil dalam bentuk fasilitas riset sehingga riset bersama ini dapat diselesaikan sesuai dengan jadwal yang telah ditetapkan sebelumnya.

\section{REFERENSI}

Abuaddous, H. Y., Al Sokkar, A. A., \& Abualodous, B. I. (2018). The impact of knowledge management on organizational performance. International Journal of Advanced Computer Science and Applications, 9(4), 204-208.

Al Khajeh, E. H. (2018). Impact of leadership styles on organizational performance. Journal of Human Resources Management Research, 1-10.

Alaarj, S., Abidin-Mohamed, Z., \& Bustamam, U. S. B. A. (2016). Mediating role of trust on the effects of knowledge management capabilities on organizational performance. ProcediaSocial and Behavioral Sciences, 235, 729-738.

Arif, S., \& Akram, A. (2018). Transformational leadership and organizational performance: the mediating role of organizational innovation. SEISENSE Journal of Management, 1(3), 5975.

BPS. (2021). Provinsi Jawa Barat dalam Angka. BPS Provinsi Jawa Barat.

Chen, J. X., Sharma, P., Zhan, W., \& Liu, L. (2019). Demystifying the impact of CEO transformational leadership on firm performance: Interactive roles of exploratory innovation and environmental uncertainty. Journal of Business Research, 85-96.

Falasca, M., Zhang, J., Conchar, M., \& Li, L. (2017). The impact of customer knowledge and marketing dynamic capability on innovation performance: an empirical analysis. Journal of Business \& Industrial Marketing.

Gomes, G., \& Wojahn, R. M. (2017). Organizational learning capability, innovation and performance: study in small and medium-sized enterprises (SMES). Revista de Administração (São Paulo), 52(2), 163-175.

Ha, S. T., Lo, M. C., \& Wang, Y. C. (2016). Relationship between knowledge management and organizational performance: a test on SMEs in Malaysia. Procedia-Social and Behavioral Sciences, 224, 184-189.

Hussinki, H., Ritala, P., Vanhala, M., \& Kianto, A. (2017). Intellectual capital, knowledge management practices and firm performance. Journal of Intellectual Capital.

Imran, M. K., Ilyas, M., \& Aslam, U. (2016). Organizational learning through transformational leadership. The Learning Organization.

Iqbal, A., Latif, F., Marimon, F., Sahibzada, U. F., \& Hussain, S. (2019). From knowledge management to organizational performance. Journal of Enterprise Information Management.

Ishak, R., \& Mansor, M. (2020). The relationship between knowledge management and organizational learning with academic staff readiness for Education 4.0. Eurasian Journal of Educational Research, 20(85), 169-184.

Jangsiriwattana, T. (2019). The relationship between transformational and transactional leadership: Employee perceptions of organizational performance and work engagement. Journal of the International Academy for Case Studies, 25(3), 1-10.

Khan, H. U. R., Ali, M., Olya, H. G., Zulqarnain, M., \& Khan, Z. R. (2018). Transformational 
Owner: Riset \& Jurnal Akuntansi

e-ISSN : 2548-9224 |p-ISSN : 2548-7507

Volume 6 Nomor 1, Januari 2022

DOI : https://doi.org/10.33395/owner.v6i1.543

leadership, corporate social responsibility, organizational innovation, and organizational performance: Symmetrical and asymmetrical analytical approaches. Corporate Social Responsibility and Environmental Management. Corporate Social Responsibility and Environmental Management, 25(6), 1270-1283.

Laeeque, S. H., Babar, S. F., \& Ahmad, H. M. (2017). The integrative determinants of innovation performance: The role of learning organization and knowledge creation. Pakistan Journal of Commerce and Social Sciences (PJCSS), 11(1), 167-184.

Lin, H. C., Dang, T. T. H., \& Liu, Y. S. (2016). CEO transformational leadership and firm performance: A moderated mediation model of TMT trust climate and environmental dynamism. Asia Pacific Journal of Management, 33(4), 981-1008.

Manzoor, F., Wei, L., Nurunnabi, M., Subhan, Q. A., Shah, S. I. A., \& Fallatah, S. (2019). The impact of transformational leadership on job performance and CSR as mediator in SMEs. Sustainability. Sustainability, 11(2), 436.

Ministry Research, T. and H. E. (2019). Higher Education Statistics.

Naderi, A., Vosta, L. N., Ebrahimi, A., \& Jalilvand, M. R. (2019). The contributions of social entrepreneurship and transformational leadership to performance. International Journal of Sociology and Social Policy.

Ngah, R., Tai, T., \& Bontis, N. (2016). Knowledge management capabilities and organizational performance in roads and transport authority of Dubai: The mediating role of learning organization. Knowledge and Process Management, 23(3), 184-193.

Novak, A. (2017). Knowledge management and organizational performance-Literature review. In Management Challenges in a Network Economy. MakeLearn and TIIM International Conference, 433-440.

Obeidat, B. Y., \& Zyod, D. S. (2015). The associations among transformational leadership, transactional leadership, knowledge sharing, job performance, and firm performance: A theoretical model. Journal of Social Sciences (COES\&RJ-JSS), 4(2), 848-866.

Obeso, M., Hernández-Linares, R., López-Fernández, M. C., \& Serrano-Bedia, A. M. (2020). Knowledge management processes and organizational performance: the mediating role of organizational learning. Journal of Knowledge Management.

Payal, R., Ahmed, S., \& Debnath, R. M. (2019). Impact of knowledge management on organizational performance. VINE Journal of Information and Knowledge Management Systems.

Rehman, S. U., Bhatti, A., \& Chaudhry, N. I. (2019). Mediating effect of innovative culture and organizational learning between leadership styles at third-order and organizational performance in Malaysian SMEs. Journal of Global Entrepreneurship Research, 9(1), 1-24.

Rijal, S. (2016). The influence of transformational leadership and organizational culture on learning organization: A comparative analysis of the IT sector, Thailand. Journal of Administrative and Business Studies, 2(3), 121-129.

Serrat, O. (2017). Knowledge solutions: Tools, methods, and approaches to drive organizational performance. Springer Nature.

Strukan, E., Nikolić, M., \& Sefić, S. (2017). Impact of Transformational Leadership on Business Performance. Tehnicki Vjesnik/Technical Gazette, 24.

Sugiyono. (2018). Metode Penelitian Kuantitatif, Kualitatif dan R\&D (28th ed.). Alfabeta.

Top, C., Abdullah, B. M. S., \& Faraj, A. H. M. (2020). Transformational leadership impact on employees' performance. Eurasian Journal of Management \& Social Sciences, 1(1), 49-59.

Torlak, N. G., \& Kuzey, C. (2019). Leadership, job satisfaction and performance links in private education institutes of Pakistan. International Journal of Productivity and Performance Management.

Vasconcelos, V. N. D. S. A., Silveira, A., \& Bizarrias, F. S. (2016). The relations between entrepreneurial orientation, organizational learning and organizational performance of small enterprises. International Journal of Professional Business Review, 1(2), 1-14.

Vashdi, D. R., Levitats, Z. S., \& Grimland, S. (2019). Which transformational leadership behaviors relate to organizational learning processes? The Learning Organization. 
Owner: Riset \& Jurnal Akuntansi

e-ISSN : 2548-9224 |p-ISSN : 2548-7507

Volume 6 Nomor 1, Januari 2022

DOI : https://doi.org/10.33395/owner.v6i1.543

Wardani, N. K., \& Eliyana, A. (2020). The Influence of Transformational Leadership on Employees Performance with Communication Satisfaction Mediation (Case Study of Frontliner Employees of PT Bank Muamalat, TBK Surabaya). 117 (Gcbme 2018), 247-252.

Widiastuti, R. (2016). Pengaruh Kepemimpinan Transformational dan Kepuasan Kerja Terhadap Komitmen Organisasional Studi pada Pegawai Pengadilan Negeri se Wilayah Yogyakarta. Universitas Gadjah Mada.

Yamin, M. (2020). Examining the role of transformational leadership and entrepreneurial orientation on employee retention with moderating role of competitive advantage. Management Science Letters, 10(2), 313-326.

Yuesti, A., \& Sumantra, K. (2017). Empowerment On The Knowledge And Learning Organization For Community Development. Scientific Research Journal (SCIRJ), 5(9). 